\title{
SÚMULA DO PROGRAMA "VIVER SEM LIMITE": PLANO NACIONAL DOS DIREITOS DA PESSOA COM DEFICIÊNCIA*
}

\begin{abstract}
o lançar o Plano Nacional dos Direitos da Pessoa com Deficiên$A$ cia - Viver sem Limite, por meio do Decreto n. 7.612, de 17 de 1 novembro de 2011, o governo federal ressalta o compromisso do Brasil com as prerrogativas da Convenção sobre os Direitos das Pessoas com Deficiência, da ONU, ratificada pelo nosso país com equivalência de emenda constitucional.

Elaborado com a participação de mais de 15 ministérios e do Conselho Nacional dos Direitos da Pessoa com Deficiência (Conade), que trouxe as contribuiçôes da sociedade civil, o Plano Viver sem Limite envolve todos os entes federados e prevê um investimento total no valor de $\mathrm{R} \$$ 7,6 bilhões até 2014 , em ações nas áreas da educação, inclusão social, acessibilidade e atenção à saúde.
\end{abstract}

\section{Acesso à educação}

Para o acesso à educação compreendem-se ações que contemplam a implantação de Salas de Recursos Multifuncionais (SRM), a promoção de acessibilidade arquitetônica nas escolas, a formação de professores para realização do Atendimento Educacional Especializado (AEE) e a aquisição de ônibus escolares acessíveis.

Em termos de formação profissional, as pessoas com deficiência são prioridade para matrícula nos cursos do Programa Nacional de Acesso ao

Esta súmula apresenta recortes do documento original, disponível em: $<$ http://www.pessoacomdeficiencia.gov.br> 
Ensino Técnico e Emprego (Pronatec). Na educação superior serão instalados núcleos de acessibilidade nas Instituições Federais de Ensino Superior (Ifes) e ofertados cursos de formação em Pedagogia, com ênfase na educação bilíngue - Língua Brasileira de Sinais (Libras)/Língua Portuguesa -, e cursos de Letras/Libras em todas as unidades da Federação.

Para promover acesso à educação de mais crianças e adolescentes com deficiência, atendidos pelo Benefício de Prestação Continuada (BPC), o Plano Viver sem Limite estabeleceu como meta ampliar as ações de monitoramento e acompanhamento que compõem o Programa BPC na Escola.

\section{Inclusão social}

Reconhecimento e participação compõem a ideia de inclusão social. Em relação às pessoas com deficiência, são necessárias medidas apropriadas para assegurar apoio e não permitir que haja discriminação baseada nas condiçôes físicas, intelectuais, mentais ou sensoriais e, muito menos, afastamento compulsório de suas comunidades.

O Plano Viver sem Limite tem como meta a efetivação do Programa BPC Trabalho, com vistas à superação de barreiras, ao fortalecimento da autonomia, do protagonismo e da participação social das pessoas com deficiência.

O Plano vai investir na implantação de Centros-Dia de Referência para pessoas com deficiência em cada unidade da Federação, com a oferta de serviços de assistência social e saúde.

Por meio da implantação de Residências Inclusivas, disponibilizará serviços de acolhimento a jovens e adultos com deficiência em situação de dependência e que estejam se desvinculando de instituições de longa permanência.

\section{Acessibilidade}

Acessibilidade é um atributo do ambiente que garante a melhoria da qualidade de vida e deve estar presente nos espaços e na comunicação. Envolve a possibilidade de todas as pessoas conviverem de forma independente, com segurança e autonomia, nos espaços, mobiliários e equipamentos abertos ao público ou de uso público. Para que pessoas com deficiência 
utilizem, em igualdade de oportunidades com as demais pessoas, o meio físico, o transporte e a informação, são necessárias medidas apropriadas para efetivar a acessibilidade.

Como parte do Plano Viver sem Limite, foi criada a Secretaria Nacional de Acessibilidade e Programas Urbanos (Snapu), dentro do Ministério das Cidades. Ela tem como objetivo promover a inserção do tema acessibilidade urbana nos projetos governamentais da União, estados, Distrito Federal e municípios, por meio da instituição de uma política nacional.

O Plano Viver sem Limite também estabelece ações relativas à construção de casas e apartamentos adaptáveis no Programa Minha Casa, Minha Vida; instalação de centros tecnológicos para formação de treinadores e instrutores de cães-guia; e instituição do Centro Nacional de Referência em Tecnologia Assistiva (CNRTA), composto por núcleos de pesquisa em universidades públicas.

Está garantido o financiamento de pesquisas para o desenvolvimento de tecnologias voltadas à inclusão de pessoas com deficiência e de produtos nacionais em tecnologia assistiva, além de projetos cooperativos entre empresas brasileiras e Instituições Científicas e Tecnológicas (ICT).

O Plano cria, ainda, linha de crédito facilitado para aquisição de serviços e equipamentos de tecnologia assistiva.

\section{Atenção à saúde}

No Brasil, foi instituído o Sistema Único de Saúde (SUS), que tem como objetivos principais dar acesso universal e atenção integral a toda a população brasileira. A Convenção sobre os Direitos das Pessoas com Deficiência reafirma esse direito e reitera que as pessoas com deficiência devem ter acesso a todos os bens e serviços da saúde, sem qualquer tipo de discriminação. O governo federal, por meio do Plano Viver sem Limite, vai ampliar o acesso e qualificar o atendimento às pessoas com deficiência (temporária ou permanente; progressiva, regressiva ou estável; intermitente ou contínua) no SUS, com foco na organização de rede e na atenção integral à saúde.

Para tanto, está sendo criada a Rede de Cuidados à Pessoa com Deficiência, que prevê uma série de estratégias e serviços de atendimento às necessidades específicas de pessoas com deficiência auditiva, física, 
visual, intelectual, múltiplas deficiências e ostomizadas. Com essa Rede, estabelece-se a articulação dos serviços de saúde, com a garantia de ações de promoção à saúde, identificação precoce de deficiências, prevenção dos agravos, tratamento e reabilitação.

Até 2014, foram planejadas diversas ações, dentre as quais se destacam: qualificação das equipes de atenção básica; criação de Centros Especializados em Reabilitação (CER) e qualificação dos serviços já existentes; criação de oficinas ortopédicas e ampliação da oferta de órteses, próteses e meios auxiliares de locomoção, vinculados aos serviços de reabilitação física do SUS; qualificação da atenção odontológica, tanto na atenção básica quanto na especializada e cirúrgica. 